\title{
Minireview
}

\section{Yet-to-be Cultured Microorganisms Relevant to Methane Fermentation Processes}

\author{
YUJI SEKIGUCHI ${ }^{1 *}$ \\ ${ }^{1}$ Microbial and Genetic Resources Research Group, Institute for Biological Resources and Functions, National \\ Institute of Advanced Industrial Science and Technology (AIST) Central 6, 1-1-1 Higashi, Tsukuba, Ibaraki \\ 305-8566, Japan
}

(Received January 1, 2006-Accepted January 19, 2006)

\begin{abstract}
Anaerobic wastewater treatment sludge represents part of the natural microbial population found in various anaerobic ecosystems. The sludge drives the degradation of organic pollutants in wastewater, generally converting complex organic compounds into carbon dioxide and methane. This anaerobic conversion (methanogenesis) relies greatly on close interaction among a variety of different trophic groups of anaerobes within the sludge. Recent culture-independent molecular inventories of the microbial community of anaerobic (methanogenic) sludges revealed a vast diversity of microbes, the majority of which have not yet been cultivated and hence whose ecophysiological functions remain largely unknown. Two ongoing challenges in this field are to explain the in situ functions of these uncultured organisms and to establish how they interact with other organisms to make the methanogenic degradation of complex organic matter possible. In this review, recent progress in the study of the composition of microbial communities and the functions of individual populations in anaerobic sludge is summarized, with a special emphasis placed on the ecology and function of yet-to-be cultured microbes. In addition, it is also emphasized that the granular sludge in upflow anaerobic sludge blanket (UASB) reactors is an ideal model ecosystem with which to explore the functions of uncultured lineages of anaerobes and to elucidate the interaction of such organisms with other trophic groups of microbes in situ.
\end{abstract}

Key words: Methanogenesis, syntrophism, wastewater treatment, 16S rRNA, uncultured microorganism

\section{Introduction}

The wealth of new data on microbial community structure and function is changing our general view of the genetic and physiological diversity of microbial life $15,22,42,43,60,64)$. Naturally occurring microorganisms in nature and humanmade ecosystems are no longer seen as simple, genetically and functionally uniform organisms but innumerably diversified means to sustain a variety of important biochemical processes. In terms of genetic diversity, this change of view is greatly attributed to the application of nucleotide se-

\footnotetext{
* Corresponding author; E-mail: y.sekiguchi@aist.go.jp, Tel: +8129-861-6590, Fax: +81-29-861-6587
}

quence-based molecular ecological techniques, particularly those targeting the $16 \mathrm{~S}$ rRNA gene, to a wide variety of environments ${ }^{42,43)}$. Using the techniques, a number of $16 \mathrm{~S}$ rRNA genes have been retrieved directly from environments ${ }^{64)}$. Subsequent comparative analysis of the gene sequences is uncovering a vast number of new lineages of descent in the domains Bacteria and Archaea. One of the key themes that have emerged through the molecular inventory is the presence of numerous types of environmentally relevant, yet-to-be cultured microbial groups (sometimes called 'clone clusters'), whose functions in situ remain largely unknown ${ }^{22,47,64)}$.

Uncultured microorganisms can be found in virtually every natural ecosystem ${ }^{15}$. Anaerobic environments are one of 
the key habitats containing uncharacterized microorganisms in abundance; examples of these environments include sediment ${ }^{44,79,89)}$, sub-surfaces ${ }^{46,81)}$ and intestinal tracts in animals ${ }^{39,58)}$. It was previously estimated that a large fraction of prokaryotes on the earth thrive in anaerobic environments: $>90 \%$ of all prokaryotic cells live under anoxic conditions $^{91)}$, making anaerobic microorganisms one of the major natural populations in our biota. It can be speculated that such a large population has an enormous capacity for harboring genetically diversified organisms. In fact, various uncharacterized phylum- and subphylum-level microbial lineages containing no cultured representatives have been identified in these ecosystems ${ }^{18,39,44,46,58,81,89)}$. Two of the ongoing challenges in this field are to explain the functions of uncultured anaerobes in ecosystems and to establish how they interact with other organisms.

Anaerobic waste/wastewater treatment technology artificially utilizes a variety of such anaerobes to drive the removal of pollutants (mainly organic matter) in waste and wastewater. The microbial communities involved in these processes (often known as 'sludge') also include a wide range of yet-to-be cultured microbes in abundance, often representing part of natural microbial populations that can be found in other anoxic ecosystems. In this review, recent progress in the study of the composition of microbial communities and the functions of individual populations in anaerobic (methanogenic) sludges is summarized, placing special emphasis on the ecology and function of yet-to-be cultured microbes relevant to methanogenic treatment processes. In addition, it is also emphasized that the granular sludge in upflow anaerobic sludge blanket (UASB) reactors is an ideal model ecosystem with which to explore the function of uncultured lineages of anaerobes, as well as to elucidate the interaction of those organisms with other trophic groups of cells.

\section{Why anaerobic sludge?}

The microbial community in anaerobic sludge represents the core component of waste/wastewater treatment processes, determining the performance of virtually every process associated with the treatment. Consequently, a thorough knowledge of the ecology of microbial communities is required in order to recognize the factors affecting the stability and development of anaerobic sludge and to develop promising strategies for reactor operations. In addition to this engineering-oriented requirement, understanding the community and function of anaerobic sludge may potentially have profound implications for understanding the anae- robes common to other anoxic environments, including yetto-be cultured organisms. In fact, given that anaerobic sludge represents part of the microbial population in naturally occurring anaerobic ecosystems, it might be used as an alternative model ecosystem to explore yet-uncharacterized anaerobes. The use of anaerobic sludge for exploring yetto-be cultured anaerobes has the following potential advantages; (1) since the sludge is generally acclimatized to the removal of particular types of organic compounds in a wastewater, it is thought to be a more simplified (specified) microbial consortium than naturally occurring microbial communities, enabling one to analyze a community more easily, (2) anaerobic waste/wastewater treatment processes are widely applied under a range of different conditions (such as at psychrophilic $\left(4-20^{\circ} \mathrm{C}\right)$, mesophilic $\left(30-40^{\circ} \mathrm{C}\right)$ and thermophilic $\left(50-60^{\circ} \mathrm{C}\right)$ temperature $\left.{ }^{85}\right)$ with different organic loading rates), providing a variety of microbial communities possessing different constituents with different functions, (3) waste/wastewater treatment processes generally involve an active biomass whose RNA content is kept at high levels, facilitating the application of rRNA-based approaches ${ }^{1)}$ and (4) enough, relatively stable microbial community samples may easily be obtained throughout an experiment (as long as the treatment process is stably maintained during that period). In this context, understanding the microbial community of anaerobic sludge does more than reveal the function of the reactor itself but may point the way toward understanding the basis of the ecological function of anaerobes (including unknown microorganisms) that are frequently found in anoxic environments. It should, however, be noted that information obtained from the organisms in such sludge samples might not directly reflect the situation in other ecosystems like natural anoxic environments. Therefore, to elucidate the function of an anoxic environment, it may be important to study the ecology of each ecosystem thoroughly in combination with the knowledge obtained from model ecosystems.

\section{Genetic diversity of prokaryotes}

As of the end of 2002, approximately 50,000 entries of $16 \mathrm{~S}$ rRNA gene sequences had been published in the public nucleotide sequence databases ${ }^{64)}, 35,000$ entries of which were derived directly from environments using molecular methods. In 2002, Hugenholtz ${ }^{42)}$ suggested in his review that the latest tally of bacterial phyla based on 16S rRNA gene sequences may be nearer 45 , and that half ( 23 phyla) of the recognized bacterial phyla contain no cultured representatives. Similarly, he suggested that the domain Archaea 
contained 18 phylum-level lineages (using the same criteria and annotation used for the recognition of bacterial phyla), of which 10 phyla had no cultured representatives ${ }^{42)}$. Rappé and Giovannoni (2003) ${ }^{64)}$ also indicated that there might be 52 bacterial phyla, in which 26 are candidate phyla containing no cultured organisms. These estimates suggested that a large portion of bacterial and archaeal phylum-level groups were not fully characterized and none of their physiological functions were determined at that point.

As of the end of 2005, the number of 16S rRNA gene sequences in databases exceeds 170,000 entries (more than three times that at the end of 2002; the entries were calculated according to Rappé and Giovannoni $(2003)^{64)}$, but the ribosomal database project already contained approximately 200,000 rRNA gene entries as of 1 December 2005 ${ }^{10)}$ ), of which approximately 70,000 were published in 2005 alone. Among these entries, $20 \%$ of sequences were from cultivated organisms, the remainder were obtained directly from environmental samples, indicating that the knowledge about environmental rRNA gene sequences had been accumulating at a surprisingly rapid rate in recent years. As the sequence databases grows, the known microbial diversity has also been expanding: $>80$ phylum-level lineages were suggested to be recognizable in the domain Bacteria in 2004, of which $80 \%$ of the phyla were not represented by cultured microbes $^{22}$ (the exact number of phylum-level groups in both prokaryotic domains is not fully resolved as of 2005, but 52 candidate bacterial phyla are already listed in the taxonomy browser at the NCBI website ${ }^{90)}$ ).

\section{Common microbial constituents in methanogenic sludge}

For anaerobic sludge, there has been a relatively limited number of studies in which a 16S rRNA gene-cloning analysis was conducted ${ }^{73)}$. However, constituents of more than 20 bacterial phyla have been detected in anaerobic (mostly methanogenic) waste and wastewater sludges used under different conditions ${ }^{7,73)}$, indicating a vast diversity of microorganisms in those ecosystems. In addition, 16S rRNA gene clones belonging to more than five archaeal classes of the phyla Euryarchaeota and Crenarchaeota have also been detected at high frequency ${ }^{73)}$. Typical $16 \mathrm{~S}$ rRNA genes frequently and commonly detected in these sludges are those of the bacterial phyla Proteobacteria (in particular Deltaproteobacteria), Firmicutes, Chloroflexi, Spirochaetes and Bacteroidetes and those of the archaeal classes (this level of phylogenetic group may correspond to the level of phylum in the domain Bacteria) Methanomicrobia, Methanobacte- ria and Thermoplasmata. In addition to these phylum- or class-level taxa, various uncultured candidate phyla (or class), such as OP10, BA024, OP8, TM6, WSA2, EM3, OS$\mathrm{K}$, OD1 and $\mathrm{C} 2$ of the archaeal phylum Crenarchaeota were detected in these sludges ${ }^{73)}$ : more than 15 different types of candidate bacterial phyla and archaeal classes were identified as significant populations in the sludges, which were also detected in other natural ecosystems as functionally unknown phylotypes. One recent finding in the predominant populations that belong to clone clusters at the phylum level in anaerobic sludge is that of the candidate bacterial phylum WWE1. The clones belonging to this cluster accounted for approximately $80 \%$ of bacterial clones analyzed in an anaerobic sludge digester ${ }^{8)}$, indicating their ecological significance in the digester sludge. However, none of the in situ functions of the organisms represented by these phylotypes is known.

One of the most important functions of waste/wastewater sludge is the methanogenic degradation of complex organic materials. Methanogenesis is a unique biochemical reaction catalyzed by a food web consisting of a diverse array of microorganisms ${ }^{68,69)}$. The methanogenic degradation of complex organic substances involves at least three different trophic groups of anaerobes, namely fermentative heterotrophs, proton-reducing syntrophic bacteria and methanogenic $\operatorname{archaea}^{68)}$. The syntrophic association (syntrophy) among proton-reducing syntrophic bacteria, hydrogen-consuming methanogens and acetate-consuming methanogens is one of the common forms of symbiotic cooperation among anaerobes in methanogenic ecosystems. Since the whole methanogenic reaction cannot proceed without this food web, close interactions are found among a variety of different trophic groups of anaerobes in ecosystems. To date, a number of anaerobes representing each trophic group have been isolated and characterized from methanogenic waste/wastewater sludge ${ }^{68,73,80)}$; anaerobic microbiologists have spent a lot of time on isolating functionally important microorganisms from methanogenic communities (e.g., see references ${ }^{45,62)}$ ). However, considering that such methanogenic communities still contained uncharacterized phenotypes in abundance, it is apparent that only a small proportion of the microorganisms and their functions in ecosystems have been elucidated.

In addition to the above examples of uncultured clades, some commonly observed, relatively significant clone clusters at the phylum to subphylum levels, members of which may represen tvthe principal constituents of anaerobic (methanogenic) reactors but are not fully characterized, are briefly mentioned below (a more general view of the community 
composition of methanogenic sludge based on 16S rRNA genes is summarized in a recent review ${ }^{73)}$ ).

\section{Putative phylum and subphylum level clades frequently found in anaerobic sludge}

\section{(1) Candidate bacterial phylum 'BA024'}

The group BA024 is a phylum level bacterial clade consisting solely of a relatively limited number of environmental 16S rRNA gene clones (the group is also called ' $\mathrm{ACl}$ ' in the NCBI taxonomy browser ${ }^{90)}$, Fig. 1). Gene clones belonging to the clade were first found in the granular sludge of a full-scale UASB reactor treating terephthalic acid wastewater, in which this phylotype accounted for $12 \%$ of all the bacterial clones analyzed in the sludge ${ }^{93)}$. Later, similar clones were found in a benzoate-degrading methanogenic consortium ${ }^{94)}$, 4-methylbenzoate-degrading methanogenic consortium ${ }^{92)}$, thermophilic $\left(55^{\circ} \mathrm{C}\right)$ methanogenic sludge treating terephthalate wastewater ${ }^{6}$, dechlorinating sludge/ consortium $^{71)}$, marine sediment ${ }^{36,46)}$, freshwater sediment ${ }^{82)}$ and paddy soil (Fig. 1). Among these ecosystems, a notably large number of $16 \mathrm{~S}$ rRNA gene clones were retrieved from the thermophilic, terephthalate-degrading methanogenic sludge $\left.^{6}\right)$ (30\% of all the bacterial clones were those of group BA024. In the original paper, the phylotypes were classified into the putative phylum OP5 under the name 'group TA55', probably because some of the TA55-type clones from the sludge involved chimeric artifacts [data not shown]). Chen et al. ${ }^{6}$ ) designed a $16 \mathrm{~S}$ rRNA-targeting probe (probe TA55_OP5) for in situ detection of the cells repre- sented by the BA024-type clones in the original thermophilic sludge, hybridizing very small, rod-shaped cells, which accounted for the second largest fraction of the bacterial population in the sludge $(25 \%$ of all the bacterial cells measured by direct fluorescence in situ hybridization [FISH] counting). Given their high occurrence in these methanogenic sludges, descendants of the BA024 branch most likely function in a major part of the food web for the methanogenic degradation of aromatic compounds. However, details of the ecophysiology of these organisms were unknown. Further analyses of the molecular ecology of these populations in sludge samples as well as attempts at cultivating them will provide their ecophysiological properties, and explain why they are so abundant in these sludge ecosystems.

\section{(2) Bacterial clone clusters 'OP8' and 'OP10' at the} phylum level

Putative bacterial phyla known as OP8 and OP10 were first recognized in the molecular inventory of a Yellowstone hot spring sediment ${ }^{44)}$. Similar phylotypes to those in OP8 have also been found in marine sediment ${ }^{52,83)}$, contaminated aquifer $^{19)}$ and a dechlorinating consortium ${ }^{72)}$. In addition, OP8-phylotypes were also present in mesophilic and thermophilic anaerobic sludges ${ }^{6,7,76)}$ and a methanogenic culture degrading 4-methylbenzoate ${ }^{92)}$. Relatively large numbers of OP8-type clones were retrieved from thermophilic $\left(55^{\circ} \mathrm{C}\right)$ sludges treating high-strength organic wastewater (5-10\% of the total bacterial clones analyzed fell into the phylum) ${ }^{6,76)}$.

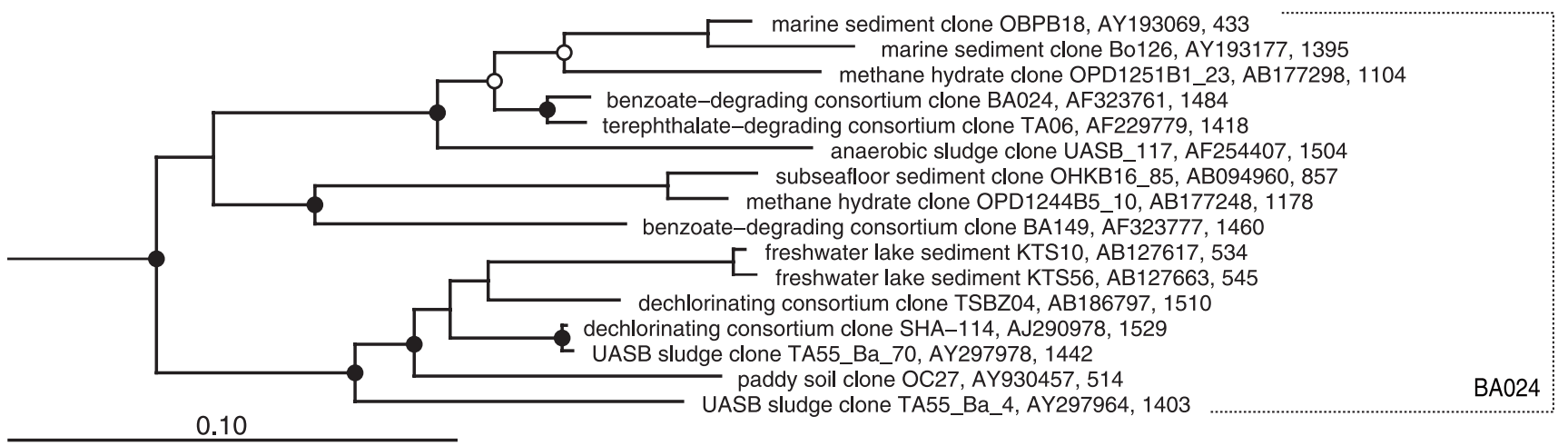

Fig. 1. Evolutionary distance dendrogram of the putative bacterial phylum 'BA024' derived from a comparative analysis of 16S rRNA gene sequences (neighbor joining tree). The tree was constructed using the ARB software package based on a sequence database deposited by Hugenholtz at the Ribosomal Database Project user-submitted alignments download site (http://rdp.cme.msu.edu/html/alignments.html) ${ }^{42}$. Branch points highly supported with bootstrap values of $>95 \%$ are indicated by solid circles, and those supported with bootstrap values of $>85 \%$ are indicated by open circles. Partial-length sequences ( $<1000$ nucleotides) were inserted into the tree using the parsimony insertion tool of ARB to show their approximate positions (the available nucleotide lengths are indicated after respective names in the tree). The scale bar represents 0.1 changes per nucleotide. 
In the putative phylum OP10, various phylotypes belonging to the clade were retrieved mainly from anoxic ecosystems such as a dechlorinating consortium ${ }^{86)}$, soil ${ }^{20)}$, wetland $^{4}$ and marine sediment ${ }^{23)}$. In some methanogenic sludges, OP10-type clones accounted for $3-8 \%$ of all the bacterial clones analyzed ${ }^{76,92)}$. The organisms represented by the OP8- and OP10-phylotypes may play a role in such ecosystems, however little about the ecophysiology of the organisms is known.

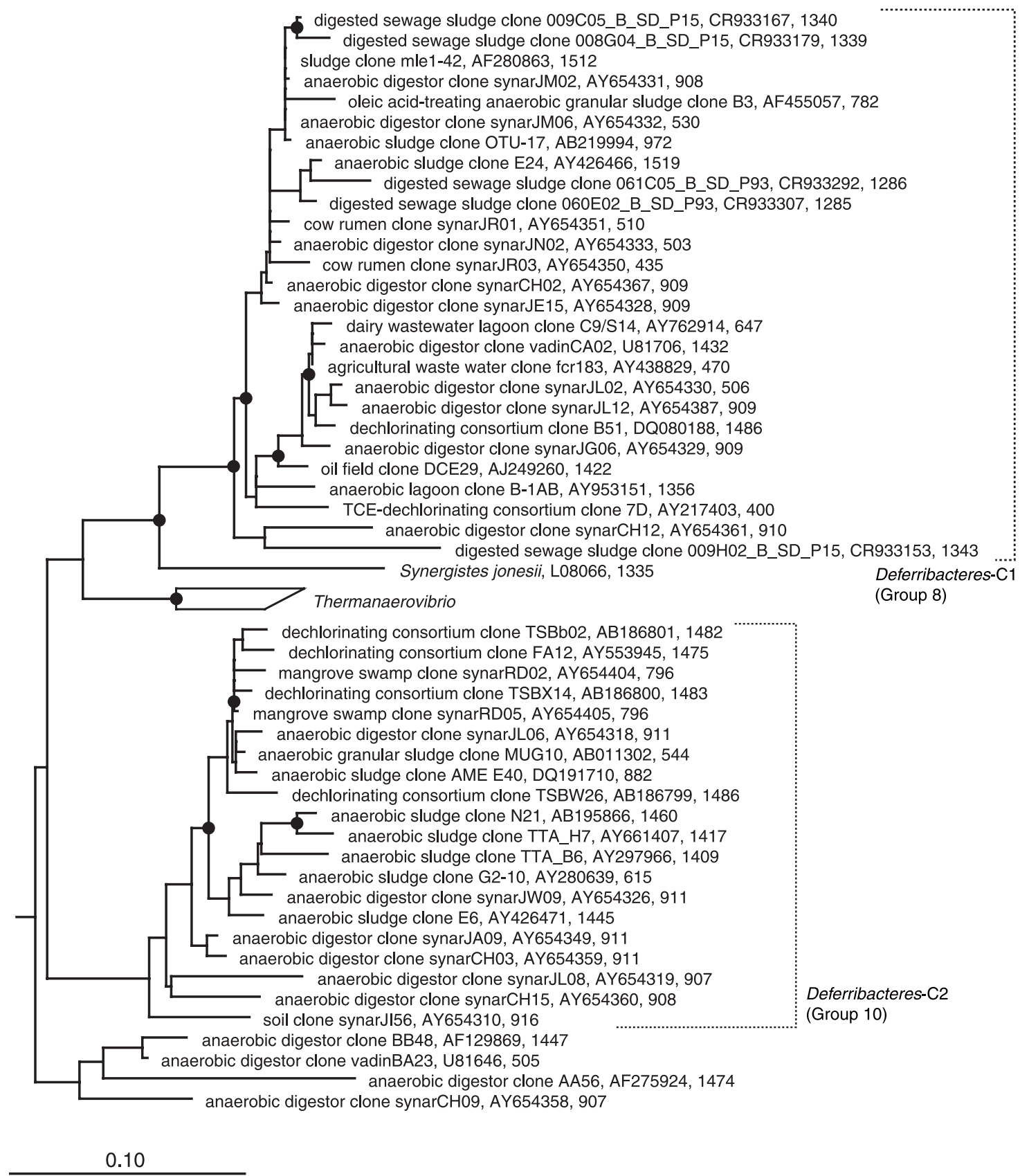

Fig. 2. Evolutionary distance dendrogram of part of the bacterial phylum Deferribacter derived from a comparative analysis of $16 \mathrm{~S}$ rRNA gene sequences. The tree was constructed using the ARB software package as mentioned in Fig. 1. Major clone lineages containing anaerobic sludge clones are shown as wedges. The scale bar represents 0.1 changes per nucleotide. 
(3) Subphylum level clone clades (Synergistes groups) in the phylum Deferribacteres

Based on the taxonomic outline of Bergey's manual (version 4,2003 ) (see also a reference $\left.{ }^{25}\right)$, the bacterial phylum Deferribacteres (formerly recognized as the phylum 'Synergistes') contains phenotypically diverse genera such as $D e-$ ferribacter, Denitrovorans, Geovibrio, Flexistipes and 'Synergistes'. However, based on comparative analyses of $16 \mathrm{~S}$ rRNA gene sequences, the phylum may also involve the anaerobic genera Thermoanaerovibrio, Anaerobaculum, Aminomonas, Anaerobaculum, Dethiosulfovibrio and Aminobacterium $^{29}$. Within the phylum, a number of $16 \mathrm{~S}$ rRNA gene clones that are distantly related to known cultivated species, forming distinct clone clusters, have been retrieved from a variety of ecosystems, such as anaerobic sludge, oral environments, sediment and animal intestines $^{29}$. For example, methanogenic wastewater treatment sludges generally contain the phylotypes as significant populations; e.g., $1-5 \%$ of all the bacterial clones analyzed fell into these uncultured clades ${ }^{7,28,76,93)}$. In addition, these populations were quantified by $16 \mathrm{~S}$ rRNA-targeted dot blot hybridization in sludge samples, showing that $1-2 \%$ of all the bacterial rRNA was from the phylum Deferribacteres ${ }^{7}$. Recently, Godon et al. ${ }^{29)}$ extensively evaluated the occurrence of Deferribacteres-phylotypes in a wide variety of environments (93 anaerobic ecosystems), such as anaerobic sludge, soils and gut ecosystems. They found that a diverse array of Deferribacteres-type clone sequences could be detected in the majority of the anaerobic ecosystems examined (mainly anaerobic sludge and termite guts). They also divided the phylum into 13 subphyla, in which subphyla 4, 7, 8 and 10 were composed mainly of environmental clones from anaerobic sludge (Fig. 2). Godon et al. ${ }^{29)}$ also suggested the ecophysiological role of the microbes represented by Deferribacteres-type phylotypes to be the degradation of amino acids under anoxic conditions, since such a trait is one of the common phenotypes of cultivated anaerobes of the phylum Deferribacteres. Given the wide-spread occurrence of these phenotypes and the recognized phenotypes of the phylum, this hypothesis may be likely. However, we still do not know why these organisms cannot be cultivated.

\section{(4) Subphylum level clone cluster in the phylum} Chlorobi

The phylum Chlorobi is currently known to consist exclusively of strictly anaerobic bacteria that generate energy from anoxygenic photosynthesis (green sulfur bacteria) ${ }^{27}$. However, a clone cluster, which is relatively distant from the class Chlorobia but forms a coherent sister clade with it, can been recognized based on 16S rRNA environmental gene sequences (Fig. 3). The subphylum level clone clade involves a variety of environmental clones from activated sludge ${ }^{9,14)}$, soil ${ }^{21}$, sediment ${ }^{88)}$ and an anaerobic benzene-degrading consortium ${ }^{84}$. In addition to these environments, such Chlorobi-phylotypes are retrieved frequently from anaerobic sludge as well (they often account for $1-10 \%$ of all the bacterial clones) ${ }^{54,76)}$, suggesting their ecological significance in these ecosystems. Considering that they could be found in anoxic, dark environments, phototrophic growth of organisms represented by the phylotypes is unlikely. Further molecular ecological study as well as their cultivation may be necessary to explain their actual ecophysiological roles in these anoxic environments.

\section{(5) Archaea: subphylum level clone cluster 'WSA2' in the phylum Euryarchaeota}

In general, most of the archaeal 16S rRNA genes retrieved from anaerobic sludge were found to be located in the phylum Euryarchaeota; clones related to members of the genera Methanosaeta, Methanosarcina, Methanospirillum, Methanobacterium and Methanothermobacter were typical ones found in these ecosystems ${ }^{73}$. However, we still have unidentifiable archaeal phylotypes whose ecophysiological functions remain unknown because they have no closely related microbes that have been cultured and characterized. Examples are those of the phylum Crenarchaeota, class Thermoplasmata and a putative clone cluster at the subphylum level (tentatively called WSA2).

A clone belonging to the cluster WSA2 was first found in anaerobic granular sludge treating organic wastewater, but this was suggested to be a minor phylotype among the clones analyzed (one of 115 prokaryotic clones) ${ }^{76}$. Similar clones were also found in anaerobic sludge ${ }^{13,55,61 \text {, }}$, sediment ${ }^{5,56)}$, contaminated aquifer ${ }^{19)}$, an oil reservoir ${ }^{30,87)}$, landfill leachate ${ }^{40)}$, deep subsurface ${ }^{37)}$ and other environments such as soils and hot springs (Fig. 4). Recently, however, WSA2-phylotypes have been found at high frequency in certain types of methanogenic sludge (they accounted for $40-67 \%$ of all the archaeal clones analyzed ${ }^{7,55)}$, suggesting the significance of these populations in particular types of treatment processes. Recently, Chouari et al. ${ }^{7)}$ developed a 16S rRNA-targeting probe to detect members of the group WSA2 (they called the clade 'Arc I'), and found they were coccus-shaped cells. They also successfully enriched members of the group using formate or hydrogen, indicative of methanogens ${ }^{7}$. At present, no further ecophysiological traits of WSA2 members are known. However, the cultures estab- 


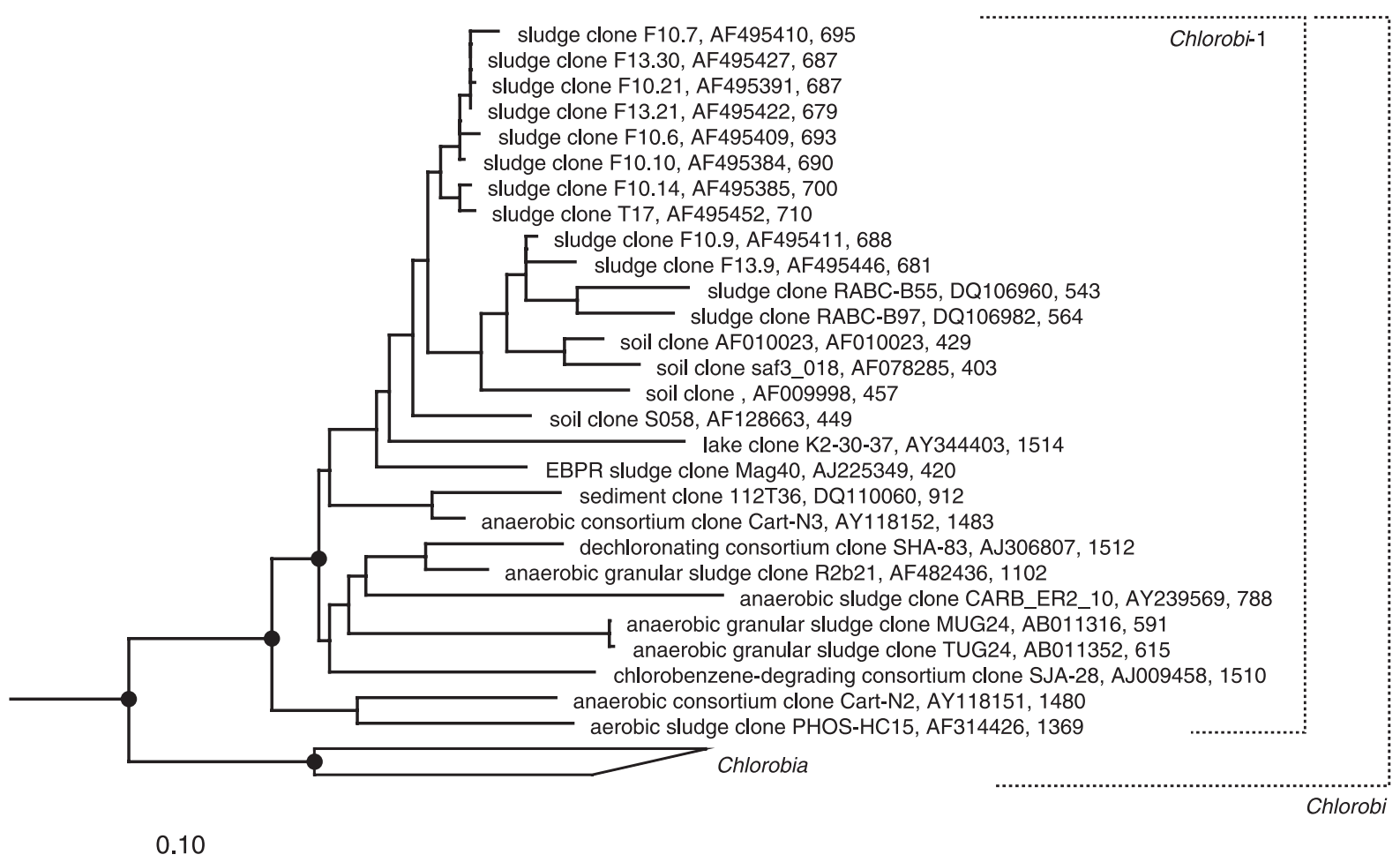

Fig. 3. Evolutionary distance dendrogram of part of the bacterial phylum Chlorobi derived from a comparative analysis of 16S rRNA gene sequences. The tree was constructed using the ARB software package as mentioned in Fig. 1 . The scale bar represents 0.1 changes per nucleotide.

lished by Chouari et al. will provide details of the physiology of the uncharacterized archaea, which are sometimes highly relevant to wastewater sludge and other anoxic environments.

(6) Subphylum level clone clade in the archaeal phylum Crenarchaeota

Various clone clades have been recognized in the archaeal phylum Crenarchaeota ${ }^{16,24,42}$. Based on comparative analyses of 16S rRNA genes, the phylum can be subdivided into more than four major clades at the subphylum level ${ }^{42,57)}$, in which the class Thermoprotei had only been the characterized lineage containing microbes that have been cultivated; the remaining subphyla were environmental clone clusters containing various 16S rRNA gene clones with no cultured representatives. Among these clone clusters of Crenarchaeota, the subphylum ' $\mathrm{Cl}$ ' (recognized well as 'marine group 1 Crenarchaeota' and also known as 'Rice cluster VI') has received the most attention particularly due to their ubiquity and abundance in marine environments. In addition, a huge number of clones were retrieved from a wide variety of ecosystems as group $\mathrm{C} 1$ phylotypes $^{70}$. Re- cently, a tangible strain belonging to group $\mathrm{C} 1$ was eventually isolated and characterized as the autotrophic ammoniaoxidizing archaeon 'Nitrosopumilus maritimus' ${ }^{488}$. In anaerobic sludge, however, none of the clones found so far fell into the subphylum $\mathrm{C} 1$.

The subphylum ' $\mathrm{C} 2$ ' is also known as a typical archaeal clone cluster containing widely distributed phylotypes found mainly in anoxic environments, such as paddy fields $^{31)}$, soils $s^{3,49}$, sediments ${ }^{38)}$ and anaerobic sludge ${ }^{8,11-}$ ${ }_{13,55,66)}$ (the group is also known as 'Rice cluster $\left(\mathrm{V}^{\prime}{ }^{31}\right)$ ). In anaerobic sludge, a significant number of C2-phylotype clones ( $3 \%$ of all the archaeal clones analyzed) were found in an anaerobic sludge treating vinasses wastewater ${ }^{28}$. In addition, various C2-type phylotypes were detected in the anaerobic digester sludge in a municipal wastewater treatment plant; Chouari et al..$^{8}$ reported that $16 \%$ of the archaeal clones fell into the subphylum C2. More recently, Collin et al. ${ }^{12)}$ surveyed Crenarchaeota rRNA genes in anaerobic granular sludge from eight UASB-type treatment plants, in which they found surprisingly high levels of uncultured Crenarchaeota-like phylotypes in five granular sludge samples $(14-78 \%$ of all the archaeal clones belong to the sub- 


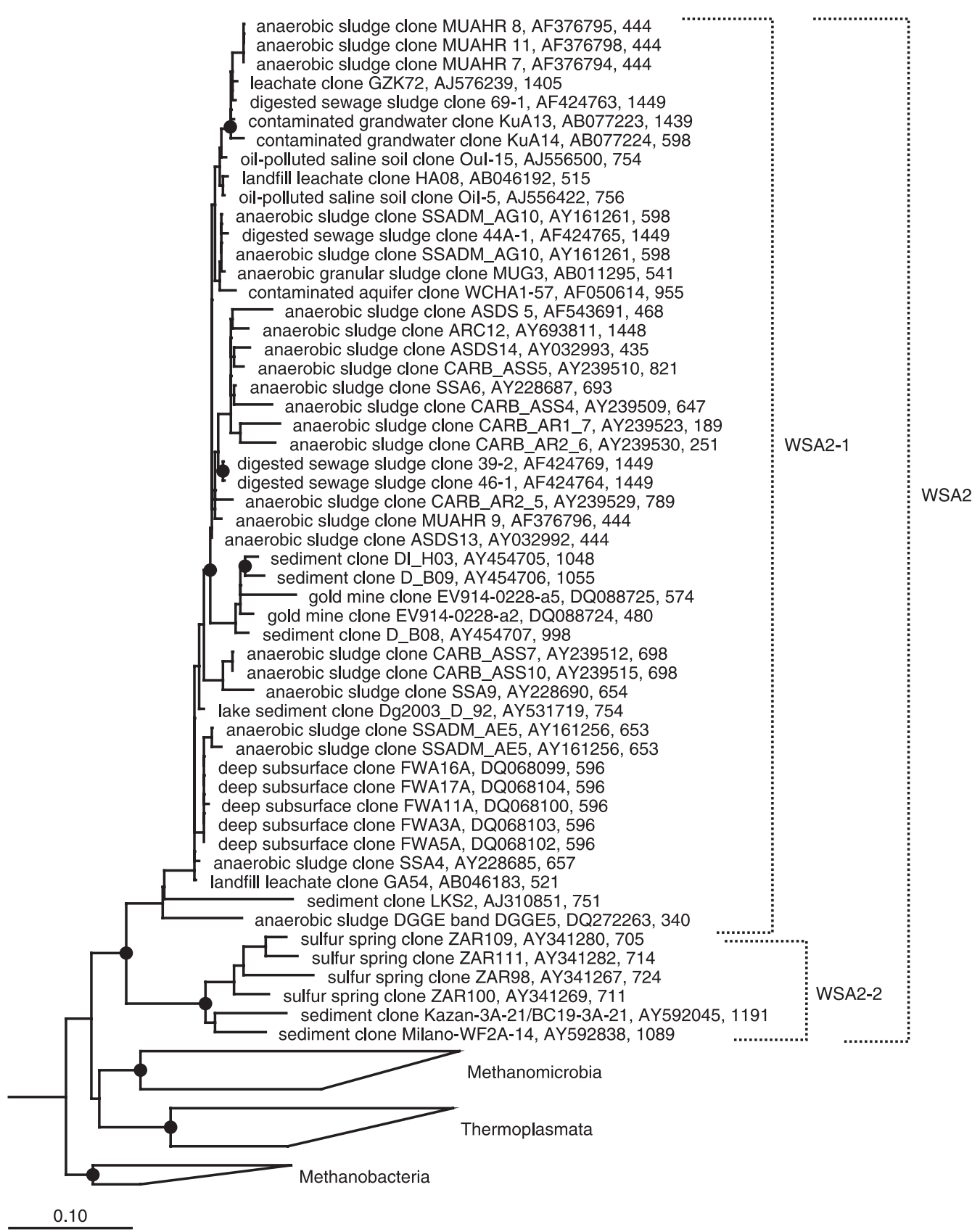

Fig. 4. Evolutionary distance dendrogram of part of the archaeal phylum Euryarchaeota derived from a comparative analysis of 16S rRNA gene sequences, highlighting the putative class 'WSA2'. The tree was constructed using the ARB software package as mentioned in Fig. 1. The scale bar represents 0.1 changes per nucleotide.

phylum C2). They also used a 16S rRNA-targeting probe to detect the cells possessing C2-phylotype genes within granule sections, finding that $15-25 \%$ of the total microbiota in the sludge reacted with the probe. The newly detected cells were rods with $1.5 \mu \mathrm{m}$ in length and $0.7 \mu \mathrm{m}$ in width forming dense clusters in sludge granule sections ${ }^{12}$. Considering the spatial distribution (the C2-type cells are juxtaposed with Methanosaeta-type cells) and abundance of these C2type organisms in sludge granules, they suggested that (1) the uncultured C2-type organisms are active members of the sludge and (2) these organisms may interact with acetateutilizing methanogens. Further studies may be needed to more clearly elucidate the ecophysiology of the populations. 


\section{Attempts to cultivate these uncultured anaerobes}

One of the obvious reasons that a large proportion of such anaerobic microbial constituents still remain largely underappreciated and understudied is the difficulty in cultivating anaerobes in the laboratory; this obstacle is particularly true for anaerobes thriving under methanogenic conditions ${ }^{47,73,74)}$. Major reasons for the difficulty are (1) anaerobes, particularly under methanogenic conditions, are generally slow growers because they can gain only a small amount of energy through thermodynamically unfavorable reactions ${ }^{68)},(2)$ they often require strictly anoxic conditions that are sometimes difficult to achieve in the laboratory and (3) most anaerobes require close interaction with other trophic groups of microbes (syntrophy) for efficient growth ${ }^{68)}$.

In general, rRNA sequence information tells nothing about ecophysiological traits as indicated above. To overcome this limitation, several techniques such as FISH combined with microautoradiography (MAR-FISH) ${ }^{59)}$, DNAbased stable isotope probing (SIP) ${ }^{63)}$ and RNA-SIP ${ }^{51,53)}$ have been developed. These provide powerful means for indirectly evaluating the substrate uptake capabilities of microbes by combining molecular techniques with cultivation-based processes. Furthermore, a metagenomic approach for microbial consortia containing yet-to-be cultured microbial cells was recently applied to a wide range of environments to gain new insight into the potential metabolic activities of predominant microbes based on gene information ${ }^{33)}$. However, it should be also noted that isolating and characterizing these microbes is important since pure cultures provide convincing information that culture-independent molecular analyses can not ${ }^{47)}$.

Cultivation of yet-to-be characterized microbes that are relevant to anaerobic treatment processes is also an important challenge, although it is a difficult task. As mentioned above, members of the putative archaeal subphylum WSA2 were recently enriched, suggesting their ecophysiological traits $^{7}$. In addition to group WSA2, examples of recent progress (mostly done by our group) in the cultivation of these yet-characterized populations in anaerobic sludge are described below, along with their closely related clones found in sludge.

\section{(1) Subphylum I of the bacterial phylum Chloroflexi}

The bacterial phylum Chloroflexi (formerly known as 'green non-sulfur bacteria' $)^{26)}$ has been well recognized as a typical bacterial phylum containing a number of diverse environmental 16S rRNA gene clones with only a few cul- tured representatives ${ }^{43)}$. The phylum Chloroflexi can be subdivided into more than four major subphyla (subphyla I, II, III and IV) on the basis of 16S rRNA gene sequences ${ }^{26,43)}$. Subphylum I contains the most diverse environmental clones among the four subphyla of Chloroflexi, e.g., clones from hot spring environments, sediment, subsurface environments, aerobic and anaerobic sludge and a contaminated aquifer ${ }^{43,73,77,95)}$. Members of subphylum I are known to be particularly widespread in anaerobic ecosystems; such clones were abundantly retrieved from various anoxic environments. Anaerobic waste/wastewater treatment sludge is also a typical habitat of these microbes; this phylotype of clones is frequently retrieved from various types of anaerobic sludge ${ }^{7,54,66,73)}$. For a long time, there were no cultured representatives of the subphylum, and therefore we were not able to determine the physiological traits of the organisms. However, very recently, pure cultures of two representative strains belonging to the subphylum, i.e., Anaerolinea thermophila and Caldilinea aerophila, have been obtained from thermophilic UASB sludge and a hot spring ${ }^{78)}$. A. thermophila was isolated from a thermophilic UASB sludge as a thermophilic, anaerobic, filamentous heterotroph. The organism could grow slowly on limited types of carbohydrate in the presence of yeast extract anaerobically. Interestingly, it grew more rapidly when it was co-cultivated with hydrogenotrophic methanogens; this implies that the organism is a "semi-syntrophic" bacterium that requires interspecies hydrogen transfer for efficient growth ${ }^{78)}$. Yamada et al. ${ }^{95)}$ also recently isolated three additional strains that belong to subphylum I. All of these strains exhibited filamentous morphotypes, and grew relatively slowly with carbohydrates in the presence of yeast extract ${ }^{95}$ ). Since yeast extract itself is also a good substrate for all known subphylum I strains, one of the ecophysiological functions of the subphylum I-type organisms may be to act as heterotrophic degraders decomposing carbohydrates as well as cellular materials (like amino acids) that are provided in its ecosystem.

\section{(2) Subclass level clone cluster 'group TA' in Deltaproteobacteria}

One unique clone cluster of Deltaproteobacteria often found in anaerobic sludge is 'group TA'. Wu et al. ${ }^{93)}$ reported the 16S rRNA gene-based community inventory of methanogenic sludge treating synthetic terephthalate-wastewater, detecting a phylogenetically independent, yet-to-becultured bacterial cluster (referred to as 'group TA') within Deltaproteobacteria. The 16S rRNA gene clones belonging to this clone cluster accounted for approximately $64 \%$ of all the bacterial clones analyzed, and these populations were 
actually found in abundance in the original sludge by subsequent in situ hybridization (these cells accounted for more than $87 \%$ of all bacterial cells based on direct counting with FISH). Due to the abundance of these populations, this new, yet-to-be-cultured group was presumed to be involved in the methanogenic degradation of terephthalate. The clone lineage was also recognized by molecular inventories of UASB granular sludge ${ }^{76,96)}$, a contaminated aquifer site ${ }^{19}$, an anaerobic trichlorobenzene-transforming consortium ${ }^{86}$ ) and an anaerobic dichloropropane-dechlorinating consortium $^{72)}$. Very recently, Qiu et al. ${ }^{62)}$ successfully enriched a culture (UI) containing thin, rod-shaped cells belonging to the group TA as the most abundant bacterial population in the culture. The culture could transform isophthalate and benzoate in syntrophic association with hydrogenotrophic methanogens ${ }^{62)}$. Given the physiology of the enrichment UI and occurrence of TA-phylotypes in the above ecosystems, members of the group TA are likely to be involved in the anaerobic food web for the methanogenic degradation of aromatic compounds such as phthalate and benzoate. In fact, Qiu et al. isolated a representative strain of the group TA from the enriched culture UI very recently, indicating the isolated organism to be an anaerobic, syntrophic aromatic compound-degrader (unpublished data). Qiu et al. ${ }^{62)}$ also noted that no substrates which support the growth of group TA cells in pure culture (without methanogens) could be found, indicative of the "obligately" syntrophic growth property of the organism.

\section{Granular sludge: a model ecosystem to explore uncultured anaerobes}

As in the case of the uncultured Crenarchaeota C2-phylotypes, the application of the full-cycle rRNA approach ${ }^{1)}$ to uncultured organisms in granular sludge often indicates more than the phylogeny of unknown organisms of interest. New insights into the spatial distribution of these uncultured cells within sludge granules (as revealed by FISH with granule sections) highlight possible physiological functions of these organisms.

Granular sludge forms spontaneously in UASB process for high-strength organic wastewater treatment. Because the sludge granules are spherical biofilms, there is a unique internal microbial architecture (e.g., layered microbial structure) within the granules. Generally, the inner layer consists mostly of aceticlastic methanogens, and the outer layer is composed of fermentative bacteria ${ }^{32,75)}$ (Fig. 5A). The spatial distributions of anaerobes within granular sludges can be clearly visualized in thin-sections of granules with $16 \mathrm{~S}$
rRNA-targeted FISH analysis using confocal laser scanning microscopy (CLSM) $)^{12,34,35,45,65,67,75,77,95)}$, revealing the wellorganized internal architecture of sludge granules. This unique architecture is considered a result of substrate profiles formed within the granules (Fig. 5B). Given that organic compounds (such as carbohydrates) in the wastewater are present on the surface of a granule, anaerobes in the outer layer of granules ferment them, producing intermediates such as fatty acids, alcohols and hydrogen within the granule. Then the organisms present in the middle layer (such as proton-reducing syntrophic bacteria) decompose these intermediates, forming acetate and hydrogen in sludge. The hydrogen concentration must be kept low for the syntrophic degradation to proceed ${ }^{68}$, hence hydrogen-consuming organisms (such as methanogens) are closely associated with syntrophic bacteria, forming syntrophic microcolonies as were described in recent papers such as Imachi et al. ${ }^{45)}$. Finally, the cells in the inner layer (such as aceticlastic methanogens) transform the remaining acetate and produce methane.

Considering this trait of sludge granules, elucidating the spatial distribution of an organism of interest may indicate its possible ecophysiological function in the anaerobic food web. In addition, identifying the microbial cells closely juxtaposed with the organism of interest using section-FISH may suggest possible substrate transfer among them. In this context, the spatial organization may be used as a model ecosystem to explore the ecophysiology of uncharacterized organisms. In fact, 16S rRNA gene cloning and the subsequent design of FISH probes have allowed us to visualize several yet-to-be cultured populations within granular sludges and to speculate on their functions in situ ${ }^{12,50,75,77,95)}$. We used the in situ hybridization technique to visualize the location of several microorganisms of particular interest in both mesophilic and thermophilic granular sludges ${ }^{45,75,77,95)}$, which were detected in our previous 16S rRNA gene cloning analysis ${ }^{76}$. In the studies, some unidentifiable bacteria, which were considered to be major bacterial components in the granules, were visualized using specifically designed and fluorescently labeled probes to reveal their in situ morphology and locations in sludge granules.

One successful case revealing the ecophysiology of yetcultured microbes is subphylum I of Chloroflexi, which was mentioned above. FISH using an oligonucleotide probe targeting 16S rRNAs of uncultured Chloroflexi-type clones first revealed that those microbes have thin filamentous cells, and predominated only in the outer-most layers of thermophilic sludge granules. Because they inhabit only the outer-most layer of the sludge granules, one of their possi- 


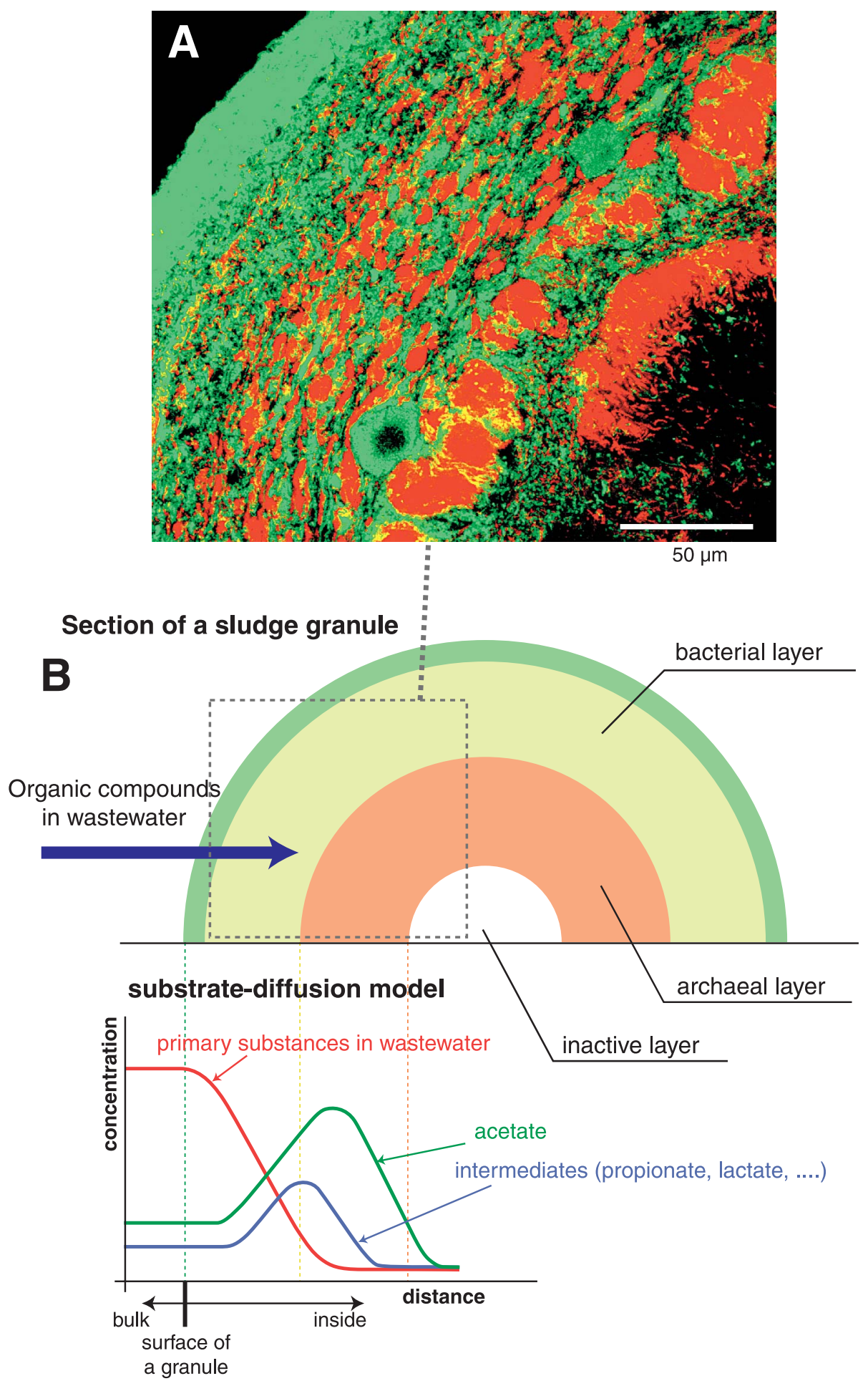

Fig. 5. (A) In situ detection of bacterial (shown as green) and archaeal (indicated as red) cells within a section of a mesophilic UASB sludge granule, viewed by $\mathrm{CLSM}^{75}$ ). (B) Schematic representation of the typical internal structure of a sludge granule, indicating a microbial layered structure. Within the granule, substrate profiles (as shown in the bottom of the figure) are thought to be formed depending on the microbial food web for the methanogenic degradation of organic matter ${ }^{32}$. 
ble physiological roles was speculated to be as a fermentative heterotroph that might degrade primary substrates in the anaerobic degradation of organic compounds, such as certain carbohydrates ${ }^{75)}$. Based on this suggested trait, the first tangible organism representing the subphylum was cultivated $^{77)}$, and later this trait was confirmed by pure culture $^{78)}$. This series of works demonstrated that granular sludge is an ideal ecosystem to study the basis of uncultured microbial life in anoxic environments.

Considering that sludge granules harbor a vast array of diverse uncultured microbes, the rRNA approach and cultivation using sludge granules may be a promising strategy to further explore uncharacterized anaerobes. In combination with this approach, visualizing the substrate uptake pattern within the granule sections with other techniques, such as radioactive tracer technique ${ }^{2)}$ plus beta imaging, SIP-Raman microscopy ${ }^{41)}$ and SIP-secondary ion mass spectrometry (SIMS $)^{17)}$, may also help to point the way to the cultivation of uncultured organisms. Collins et al. ${ }^{12)}$ attempted to apply the radioactive tracer technique and beta imaging to sludge granules in order to speculate on the function of yet-cultured Crenarchaeota cells, suggesting that they are closely associated with organisms uptaking acetate.

Linking the microbial community and community functions may be the next exciting frontier in microbial ecology. However, much more knowledge on the ecophysiology of individual populations, particularly those of uncultured lineages, may be needed to convincingly do this. Cultivation (or characterization with much more sophisticated methods) of currently uncharacterized microbes using model ecosystems, like granular sludge, will provide substantial information for further understanding anoxic biota.

\section{Acknowledgements}

I thank Hiroyuki Imachi at Nagaoka University of Technology for valuable suggestions and discussions.

\section{References}

1) Amann, R.I., W. Ludwig and K.-H. Schleifer. 1995. Phylogenetic identification and in situ detection of individual microbial cells without cultivation. Microbiol. Rev. 59: 143-169.

2) Andreasen, K. and P.H. Nielsen. 1997. Application of microautoradiography to the study of substrate uptake by filamentous microorganisms in activated sludge. Appl. Environ. Microbiol. 63: $3662-3668$.

3) Bintrim, S.B., T.J. Donohue, J. Handelsman, G.P. Roberts and R.M. Goodman. 1997. Molecular phylogeny of archaea from soil. Proc. Natl. Acad. Sci. USA 94: 277-282.
4) Brofft, J.E., J.V. McArthur and L.J. Shimkets. 2002. Recovery of novel bacterial diversity from a forested wetland impacted by reject coal. Environ. Microbiol. 4: 764-769.

5) Chan, O.C., P. Claus, P. Casper, A. Ulrich, T. Lueders and R. Conrad. 2005. Vertical distribution of structure and function of the methanogenic archaeal community in Lake Dagow sediment. Environ. Microbiol. 7: 1139-1149.

6) Chen, C.L., H. Macarie, I. Ramirez, A. Olmos, S.L. Ong, O. Monroy and W.T. Liu. 2004. Microbial community structure in a thermophilic anaerobic hybrid reactor degrading terephthalate. Microbiology 150: 3429-3440.

7) Chouari, R., D. Le Paslier, P. Daegelen, P. Ginestet, J. Weissenbach and A. Sghir. 2005. Novel predominant archaeal and bacterial groups revealed by molecular analysis of an anaerobic sludge digester. Environ. Microbiol. 7: 1104-1115.

8) Chouari, R., D. Le Paslier, C. Dauga, P. Daegelen, J. Weissenbach and A. Sghir. 2005. Novel major bacterial candidate division within a municipal anaerobic sludge digester. Appl. Environ. Microbiol. 71: 2145-2153.

9) Christensson, M., L.L. Blackall and T. Welander. 1998. Metabolic transformations and characterisation of the sludge community in an enhanced biological phosphorus removal system. Appl. Microbiol. Biotechnol. 49: 226-234.

10) Cole, J.R., B. Chai, R.J. Farris, Q. Wang, S.A. Kulam, D.M. McGarrell, G.M. Garrity and J.M. Tiedje. 2005. The Ribosomal Database Project (RDP-II): sequences and tools for high-throughput rRNA analysis. Nucleic Acids Res. 33: D294-D296.

11) Collins, G., C. Foy, S. McHugh and V. O'Flaherty. 2005. Anaerobic treatment of 2,4,6-trichlorophenol in an expanded granular sludge bed-anaerobic filter (EGSB-AF) bioreactor at 15 degrees C. FEMS Microbiol. Ecol. 53: 167-178.

12) Collins, G., T. Mahony, S. McHugh, A. Gieseke, D. de Beer and V. O'Flaherty. 2005. Distribution, dynamics and in situ ecophysiology of Crenarchaeota in anaerobic wastewater treatment granular biofilms. Wat. Sci. Tech. 52: 233-239.

13) Collins, G., A. Woods, S. McHugh, M.W. Carton and V. O'Flaherty. 2003. Microbial community structure and methanogenic activity during start-up of psychrophilic anaerobic digesters treating synthetic industrial wastewaters. FEMS Microbiol. Ecol. 46: 159-170.

14) Dabert, P., B. Sialve, J.P. Delgenes, R. Moletta and J.J. Godon. 2001. Characterisation of the microbial $16 \mathrm{~S}$ rDNA diversity of an aerobic phosphorus-removal ecosystem and monitoring of its transition to nitrate respiration. Appl. Microbiol. Biotechnol. 55: 500-509.

15) Delong, E.E. and N.R. Pace. 2001. Environmental diversity of Bacteria and Archaea. Syst. Biol. 50: 470-478.

16) Delong, E.F. 1992. Archaea in Coastal Marine Environments. Proc. Natl. Acad. Sci. USA 89: 5685-5689.

17) DeRito, C.M., G.M. Pumphrey and E.L. Madsen. 2005. Use of field-based stable isotope probing to identify adapted populations and track carbon flow through a phenol-degrading soil microbial community. Appl. Environ. Microbiol. 71: 7858-7865.

18) Dojka, M.A., J.K. Harris and N.R. Pace. 2000. Expanding the known diversity and environmental distribution of an uncultured phylogenetic division of bacteria. Appl. Environ. Microbiol. 66: $1617-1621$

19) Dojka, M.A., P. Hugenholtz, S.K. Haack and N.R. Pace. 1998. Microbial diversity in a hydrocarbon- and chlorinated-solventcontaminated aquifer undergoing intrinsic bioremediation. Appl. 
Environ. Microbiol. 64: 3869-3877.

20) Dunbar, J., S.M. Barns, L.O. Ticknor and C.R. Kuske. 2002. Empirical and theoretical bacterial diversity in four Arizona soils. Appl. Environ. Microbiol. 68: 3035-3045.

21) Dunbar, J., S. Takala, S.M. Barns, J.A. Davis and C.R. Kuske. 1999. Levels of bacterial community diversity in four arid soils compared by cultivation and 16S rRNA gene cloning. Appl. Environ. Microbiol. 65: 1662-1669.

22) Fox, J.L. 2005. Ribosomal gene milestone met, already left in dust. ASM News 71: 6-7.

23) Freitag, T.E. and J.I. Prosser. 2003. Community structure of ammonia-oxidizing bacteria within anoxic marine sediments. Appl. Environ. Microbiol. 69: 1359-1371.

24) Fuhrman, J.A., K. Mccallum and A.A. Davis. 1992. Novel Major Archaebacterial Group from Marine Plankton. Nature 356: 148 149.

25) Garrity, G.E. and J.G. Holt. 2001. Phylum BIX. Deferribacteres phy. nov., pp. 465-474. In D.R. Boone and R.W. Castenholz (ed.), Bergey's manual of systematic bacteriology. SpringerVerlag, New York.

26) Garrity, G.E. and J.G. Holt. 2001. Phylum BVI. Chloroflexi phy. nov., pp. 427-446. In G.M. Garrity (ed.), Bergey's manual of systematic bacteriology., Second edition ed, vol. one. SpringerVerlag, New York.

27) Garrity, G.E. and J.G. Holt. 2001. Phylum BXI. Chlorobi phy. nov., pp. 601-623. In D.R. Boone and R.W. Castenholz (ed.), Bergey's manual of systematic bacteriology. Springer-Verlag, New York.

28) Godon, J.-J., E. Zumstein, P. Dabert, F. Habouzit and R. Moletta. 1997. Molecular microbial diversity of an anaerobic digestor as determined by small-subunit rDNA sequence analysis. Appl. Environ. Microbiol. 63: 2802-2813.

29) Godon, J.J., J. Moriniere, M. Moletta, M. Gaillac, V. Bru and J.P. Delgenes. 2005. Rarity associated with specific ecological niches in the bacterial world: the 'Synergistes' example. Environ. Microbiol. 7: 213-224.

30) Grabowski, A., O. Nercessian, F. Fayolle, D. Blanchet and C. Jeanthon. 2005. Microbial diversity in production waters of a low-temperature biodegraded oil reservoir. FEMS Microbiol. Ecol. 54: 427-443.

31) Grosskopf, R., S. Stubner and W. Liesack. 1998. Novel euryarchaeotal lineages detected on rice roots and in the anoxic bulk soil of flooded rice microcosms. Appl. Environ. Microbiol. 64: 4983-4989.

32) Guiot, S.R., A. Pauss and J.W. Costerton. 1992. A structured model of the anaerobic granule consortium. Wat. Sci. Tech. 25: $1-10$.

33) Handelsman, J. 2005. Metagenomics: Application of genomics to uncultured microorganisms (vol. 68, p. 669, 2004). Microbiol. Mol. Biol. Rev. 69: 195-195.

34) Harmsen, H.J.M., A.D.L. Akkermans, A.J. Stams and W.M. de Vos. 1996. Population dynamics of propionate-oxidizing bacteria under methanogenic and sulfidogenic conditions in anaerobic granular sludge. Appl. Environ. Microbiol. 62: 2163-2168.

35) Harmsen, H.J.M., H.M.P. Kengen, A.D.L. Akkermans, A.J.M. Stams and W.M. de Vos. 1996. Detection and localization of syntrophic propionate-oxidizing bacteria in granular sludge by in situ hybridization using 16S rRNA-based oligonucleotide probes. Appl. Environ. Microbiol. 62: 1656-1663.

36) Harris, J.K., S.T. Kelley and N.R. Pace. 2004. New perspective on uncultured bacterial phylogenetic division OP11. Appl. Environ. Microbiol. 70: 845-849.

37) Heijs, S.K., J.S.S. Damste and L.J. Forney. 2005. Characterization of a deep-sea microbial mat from an active cold seep at the Milano mud volcano in the Eastern Mediterranean Sea. FEMS Microbiol. Ecol. 54: 47-56.

38) Hershberger, K.L., S.M. Barns, A.L. Reysenbach, S.C. Dawson and N.R. Pace. 1996. Wide diversity of Crenarchaeota. Nature 384: $420-420$.

39) Hongoh, Y., P. Deevong, T. Inoue, S. Moriya, S. Trakulnaleamsai, M. Ohkuma, C. Vongkaluang, N. Noparatnaraporn and T. Kudol. 2005. Intra- and interspecific comparisons of bacterial diversity and community structure support coevolution of gut microbiota and termite host. Appl. Environ. Microbiol. 71: 65906599.

40) Huang, L.N., Y.Q. Chen, H. Zhou, S. Luo, C.Y. Lan and L.H. Qu. 2003. Characterization of methanogenic Archaea in the leachate of a closed municipal solid waste landfill. FEMS Microbiol. Ecol. 46: 171-177.

41) Huang, W.E., R.I. Griffiths, I.P. Thompson, M.J. Bailey and A.S. Whiteley. 2004. Raman microscopic analysis of single microbial cells. Anal. Chem. 76: 4452-4458.

42) Hugenholtz, P. 2002. Exploring prokaryotic diversity in the genomic era. Genome Biol. 3: reviews 0003.1-003.8.

43) Hugenholtz, P., B.M. Goebel and N.R. Pace. 1998. Impact of culture-independent studies on the emerging phylogenetic view of bacterial diversity. J. Bacteriol. 180: 4765-4774.

44) Hugenholtz, P., C. Pitulle, K.L. Hershberger and N.R. Pace. 1998. Novel division level bacterial diversity in a yellowstone hot spring. J. Bacteriol. 180: 366-376.

45) Imachi, H., Y. Sekiguchi, Y. Kamagata, A. Ohashi and H. Harada. 2000. Cultivation and in situ detection of a thermophilic bacterium capable of oxidizing propionate in syntrophic association with hydrogenotrophic methanogens in a thermophilic methanogenic granular sludge. Appl. Environ. Microbiol. 66: 3608-3615.

46) Inagaki, F., M. Suzuki, K. Takai, H. Oida, T. Sakamoto, K. Aoki, K.H. Nealson and K. Horikoshi. 2003. Microbial communities associated with geological horizons in coastal subseafloor sediments from the Sea of Okhotsk. Appl. Environ. Microbiol. 69: 7224-7235.

47) Kamagata, Y. and H. Tamaki. 2005. Cultivation of uncultured fastidious microbes. Microbes Environ. 20: 85-91.

48) Könneke, M., A.E. Bernhard, J.R. de la Torre, C.B. Walker, J.B. Waterbury and D.A. Stahl. 2005. Isolation of an autotrophic ammonia-oxidizing marine archaeon. Nature 437: 543-546.

49) Kudo, Y., T. Nakajima, T. Miyaki and H. Oyaizu. 1997. Methanogen flora of paddy soils in Japan. FEMS Microbiol. Ecol. 22: $39-48$.

50) Liu, W.-T., O.-C. Chan and H.H.P. Fang. 2002. Characterization of microbial community in granular sludge treating brewery wastewater. Water Res. 36: 1767-1775.

51) MacGregor, B.J., V. Bruchert, S. Fleischer and R. Amann. 2002. Isolation of small-subunit rRNA for stable isotopic characterization. Environ. Microbiol. 4: 451-464.

52) Madrid, V.M., G.T. Taylor, M.I. Scranton and A.Y. Chistoserdov. 2001. Phylogenetic diversity of bacterial and archaeal communities in the anoxic zone of the Cariaco Basin. Appl. Environ. Microbiol. 67: 1663-1674.

53) Manefield, M., A.S. Whiteley, R.I. Griffiths and M.J. Bailey. 2002. RNA stable isotope probing, a novel means of linking mi- 
crobial community function to phylogeny. Appl. Environ. Microbiol. 68: 5367-5373.

54) Mchugh, S., M. Carton, G. Collins and V. O'Flaherty. 2004. Reactor performance and microbial community dynamics during anaerobic biological treatment of wastewaters at 16-37 degrees C. FEMS Microbiol. Ecol. 48: 369-378.

55) McHugh, S., M. Carton, T. Mahony and V. O'Faherty. 2003. Methanogenic population structure in a variety of anaerobic bioreactors. FEMS Microbiol. Lett. 219: 297-304.

56) Nusslein, B., K.J. Chin, W. Eckert and R. Conrad. 2001. Evidence for anaerobic syntrophic acetate oxidation during methane production in the profundal sediment of subtropical Lake Kinneret (Israel). Environ. Microbiol. 3: 460-470.

57) Ochsenreiter, T., D. Selezi, A. Quaiser, L. Bonch-Osmolovskaya and C. Schleper. 2003. Diversity and abundance of Crenarchaeota in terrestrial habitats studied by $16 \mathrm{~S}$ RNA surveys and real time PCR. Environ. Microbiol. 5: 787-797.

58) Ohkuma, M., K. Ohtoko, C. Grunau, S. Moriya and T. Kudo. 1998. Phylogenetic identification of the symbiotic hypermastigote Trichonympha agilis in the hindgut of the termite Reticulitermes speratus based on small-subunit rRNA sequence. J. Eukaryot. Microbiol. 45: 439-444.

59) Okabe, S., T. Kindaichi and T. Ito. 2004. MAR-FISH-An ecophysiological approach to link phylogenetic affiliation and in situ metabolic activity of microorganisms at a single-cell resolution. Microbes Environ. 19: 83-98.

60) Pace, N.R. 1999. Microbial ecology \& diversity. ASM News 65: 328-333.

61) Pender, S., M. Toomey, M. Carton, D. Eardly, J.W. Patching, E. Colleran and V. O'Flaherty. 2004. Long-term effects of operating temperature and sulphate addition on the methanogenic community structure of anaerobic hybrid reactors. Water Res. 38: 619630.

62) Qiu, Y.-L., Y. Sekiguchi, H. Imachi, Y. Kamagata, I.-C. Tseng, S.-S. Cheng, A. Ohashi and S. Hanada. 2004. Identification and isolation of anaerobic, syntrophic phthalate isomers-degrading microbes from methanogenic sludges treating wastewater from terephthalate manufacturing. Appl. Environ. Microbiol. 70: $1617-1626$

63) Radajewski, S., P. Ineson, N.R. Parekh and J.C. Murrell. 2000. Stable-isotope probing as a tool in microbial ecology. Nature 403: 646-649.

64) Rappé, M.S. and S.J. Giovannoni. 2003. The uncultured microbial majority. Annu. Rev. Microbiol. 57: 369-394.

65) Rocheleau, S., C.W. Greer, J.R. Lawrence, C. Cantin, L. Laramee and S.R. Guiot. 1999. Differentiation of Methanosaeta concilii and Methanosarcina barkeri in anaerobic mesophilic granular sludge by fluorescent in situ hybridization and confocal scanning laser microscopy. Appl. Environ. Microbiol. 65: 2222-2229.

66) Roest, K., H.G.H.J. Heilig, H. Smidt, W.M. de Vos, A.J.M. Stams and A.D.L. Akkermans. 2005. Community analysis of a full-scale anaerobic bioreactor treating paper mill wastewater. Syst. Appl. Microbiol. 28: 175-185.

67) Santegoeds, C.M., L.R. Damgaard, G. Hesselink, J. Zopfi, P. Lens, G. Muyzer and D. de Beer. 1999. Distribution of sulfate-reducing and methanogenic bacteria in anaerobic aggregates determined by microsensor and molecular analyses. Appl. Environ. Microbiol. 65: 4618-4629.

68) Schink, B. 1997. Energetics of syntrophic cooperation in methanogenic degradation. Microbiol. Mol. Biol. Rev. 61: 262-280.
69) Schink, B. 1992. Syntrophism among prokaryotes., pp. 276-299. In A. Balows, H.G. Truper, M. Dworkin, W. Harder and K.-H. Schleifer (ed.), The prokaryotes. Springer-Verlag, Newyork.

70) Schleper, C., G. Jurgens and M. Jonuscheit. 2005. Genomic studies of uncultivated archaea. Nat. Rev. Microbiol. 3: 479-488.

71) Schlotelburg, C., C. von Wintzingerode, R. Hauck, F. von Wintzingerode, W. Hegemann and U.B. Gobel. 2002. Microbial structure of an anaerobic bioreactor population that continuously dechlorinates 1,2-dichloropropane. FEMS Microbiol. Ecol. 39: 229-237.

72) Schlotelburg, C., F. von Wintzingerode, R. Hauck, W. Hegemann and U.B. Geobel. 2000. Bacteria of an anaerobic 1,2-dichloropropane-dechlorinating mixed culture are phylogenetically related to those of other anaerobic dechlorinating consortia. Int. J. Syst. Evol. Microbiol. 50: 1505-1511.

73) Sekiguchi, Y. and Y. Kamagata. 2004. Microbial community structure and functions in methane fermentation technology for wastewater treatment., pp. 361-384. In P. Zuber and M.M. Nakano (ed.), Strict and facultative anaerobes: medical and environmental aspects. Horizon Scientific Press, Norfolk, UK.

74) Sekiguchi, Y., Y. Kamagata and H. Harada. 2001. Recent advances in methane fermentation technology. Curr. Opin. Biotechnol. 12: 277-282.

75) Sekiguchi, Y., Y. Kamagata, K. Nakamura, A. Ohashi and H. Harada. 1999. Fluorescence in situ hybridization using 16S rRNA-targeted oligonucleotides reveals localization of methanogens and selected uncultured bacteria in mesophilic and thermophilic sludge granules. Appl. Environ. Microbiol. 65: 1280-1288.

76) Sekiguchi, Y., Y. Kamagata, K. Syutsubo, A. Ohashi, H. Harada and K. Nakamura. 1998. Phylogenetic diversity of mesophilic and thermophilic granular sludges determined by $16 \mathrm{~S}$ rRNA gene analysis. Microbiology 144: 2655-2665.

77) Sekiguchi, Y., H. Takahashi, Y. Kamagata, A. Ohashi and H. Harada. 2001. In situ detection, isolation, and physiological properties of a thin filamentous microorganism abundant in methanogenic granular sludges: a novel isolate affiliated with a clone cluster, the green non-sulfur bacteria, subdivision I. Appl. Environ. Microbiol. 67: 5740-5749.

78) Sekiguchi, Y., T. Yamada, S. Hanada, A. Ohashi, H. Harada and Y. Kamagata. 2003. Anaerolinea thermophila gen. nov., sp. nov. and Caldilinea aerophila gen. nov., sp. nov., novel filamentous thermophiles that represent a previously uncultured lineage of the domain Bacteria at the subphylum level. Int. J. Syst. Evol. Micribiol. 53: 1843-1851.

79) Spring, S., R. Schulze, J. Overmann and K.H. Schleifer. 2000. Identification and characterization of ecologically significant prokaryotes in the sediment of freshwater lakes: molecular and cultivation studies. FEMS Microbiol. Rev. 24: 573-590.

80) Stams, A.J.M. and S.J.W.H. Oude Elferink. 1997. Understanding and advancing wastewater treatment. Curr. Opin. Biotechnol. 8: 328-334.

81) Takai, K. and K. Horikoshi. 1999. Genetic diversity of archaea in deep-sea hydrothermal vent environments. Genetics 152: 12851297.

82) Tamaki, H., Y. Sekiguchi, S. Hanada, K. Nakamura, N. Nomura, M. Matsumura and Y. Kamagata. 2005. Comparative analysis of bacterial diversity in freshwater sediment of a shallow eutrophic lake by molecular and improved cultivation-based techniques. Appl. Environ. Microbiol. 71: 2162-2169.

83) Teske, A., K.U. Hinrichs, V. Edgcomb, A.D. Gomez, D. Kysela, 
S.P. Sylva, M.L. Sogin and H.W. Jannasch. 2002. Microbial diversity of hydrothermal sediments in the Guaymas Basin: Evidence for anaerobic methanotrophic communities. Appl. Environ. Microbiol. 68: 1994-2007.

84) Ulrich, A.C. and E.A. Edwards. 2003. Physiological and molecular characterization of anaerobic benzene-degrading mixed cultures. Environ. Microbiol. 5: 92-102.

85) van Lier, J.B., S. Rebac and G. Lettinga. 1997. High-rate anaerobic wastewater treatment under psychrophilic and thermophilic conditions. Wat. Sci. Tech. 35: 199-206.

86) von Wintzingerode, F., B. Selent, W. Hegemann and U.B. Göbel. 1999. Phylogenetic analysis of an anaerobic, trichlorobenzene-transforming microbial consortium. Appl. Environ. Microbiol. 65: 283-286.

87) Watanabe, K., Y. Kodama, N. Hamamura and N. Kaku. 2002. Diversity, abundance, and activity of archaeal populations in oilcontaminated groundwater accumulated at the bottom of an underground crude oil storage cavity. Appl. Environ. Microbiol. 68: 3899-3907.

88) Weber, K.A., M.M. Urrutia, P.F. Churchill, R.K. Kukkadapu and E.E. Roden. 2006. Anaerobic redox cycling of iron by freshwater sediment microorganisms. Environ. Microbiol. 8: 100-113.

89) Webster, G., R.J. Parkes, J.C. Fry and A.J. Weightman. 2004. Widespread occurrence of a novel division of bacteria identified by $16 \mathrm{~S}$ rRNA gene sequences originally found in deep marine Sediments. Appl. Environ. Microbiol. 70: 5708-5713.

90) Wheeler, D.L., T. Barrett, D.A. Benson, S.H. Bryant, K. Canese, D.M. Church, M. Di Cuccio, R. Edgar, S. Federhen, W. Helm- berg, D.L. Kenton, O. Khovayko, D.J. Lipman, T.L. Madden, D.R. Maglott, J. Ostell, J.U. Pontius, K.D. Pruitt, G.D. Schuler, L.M. Schriml, E. Sequeira, S.T. Sherry, K. Sirotkin, G. Starchenko, T.O. Suzek, R. Tatusov, T.A. Tatusova, L. Wagner and E. Yaschenko. 2005. Database resources of the National Center for Biotechnology Information. Nucleic Acids Res. 33: D39-D45.

91) Whitman, W.B., D.C. Coleman and W.J. Wiebe. 1998. Prokaryotes: The unseen majority. Proc. Natl. Acad. Sci. USA 95: 65786583.

92) Wu, J.-H., W.-T. Liu, I.-C. Tseng and S.-S. Cheng. 2001. Characterization of a 4-methylbenzoate-degrading methanogenic consortium as determined by small-subunit rDNA sequence analysis. J. Biosci. Bioeng. 91: 449-455.

93) Wu, J.-H., W.-T. Liu, I.-C. Tseng and S.-S. Cheng. 2001. Characterization of microbial consortia in a terephthalate-degrading anaerobic granular sludge system. Microbiology 147: 373-382.

94) Wu, J.-H., I.-C. Tseng, W.-T. Liu and S.-S. Cheng. 2001. Presented at the 9th World Congress on Anaerobic Digestion, Antwerpen, Sept. 2-5.

95) Yamada, T., Y. Sekiguchi, H. Imachi, Y. Kamagata, A. Ohashi and S. Hanada. 2005. Diversity, localization and physiological properties of filamentous microbes belonging to Chloroflexi subphylum I in mesophilic and thermophilic methanogenic sludge granules. Appl. Environ. Microbiol. 71: 7493-7503.

96) Zhang, T., S.Z. Ke and H.H.P. Fang. 2005. Microbial characteristics of a methanogenic phenol-degrading sludge. Wat. Sci. Tech. 52: $73-78$. 